\title{
Traumatic bilateral L4-5 facet fracture dislocation: a case presentation with mechanism of injury
}

\author{
Kevin Chi Him Fok and Jason Pui Yin Cheung ${ }^{*}$ (D)
}

\begin{abstract}
Background: Traumatic bilateral locked facet joints at $L 4-5$ level are a rare entity. A careful review only revealed four case reports. This case presented with an unusual mechanism of injury.

Case presentation: We present a case of a 40-year-old male who suffered bilateral $L 4-5$ traumatic facet fracture dislocation following a fall injury. The dislocation was associated with fractures of bilateral L4 inferior articular processes, left L4 pedicle, L4 spinous process and postero-inferior body of L4. He presented with cauda-equina syndrome and underwent emergency decompression, reduction and instrumented fusion.

Conclusion: The biomechanics of the lumbar spine may differ with each individual. L4-5 dislocation may be a variant to lumbosacral (L5-S1) dislocation, owing to hyperextension injury.
\end{abstract}

Keywords: Traumatic spondylolisthesis, Locked facet, Jumped facet, L4-5

\section{Background}

Traumatic facet dislocation in the lower lumbar spine is rare, with only handful of reported cases with lumbosacral (L5-S1) dislocation. We present a case of a young male with bilateral L4 -5 traumatic facet dislocation after a fall injury.

\section{Case presentation}

A 40-year-old male was involved in an industrial accident. He fell backwards with his back landing onto a metal bar, while another person landed on his thighs which caused a hyperextension moment across his lumbar spine. He experienced immediate pain over the lower back with numbness in bilateral legs.

Physical examination upon arrival showed weakness of both lower extremities. The hip flexion (L2) and knee extension (L3) were Medical Research Council (MRC) grade $2 / 5$ on both sides, and ankle dorsiflexors (L4), long toe extensors (L5) and ankle plantar flexors (S1) were grade 0/5 on both sides. There was absent of sensation by light touch and pin prick over L5 to S1 dermatomes on both

\footnotetext{
* Correspondence: cheungjp@hku.hk

Department of Orthopaedics and Traumatology, The University of Hong Kong, Pokfulam, Hong Kong SAR, China
}

sides. The lower limb reflexes were absent. Per-rectal examination showed absence of deep anal pressure, perianal sensation and voluntary grip. Clinically, the patient had cauda equina syndrome. There was a horizontal patch of bruising over the thoracolumbar region of the back, resulting from the collision with a metal bar (Fig. 1a).

$\mathrm{X}$-ray and Computed tomography showed grade II traumatic spondylolisthesis of L4 on L5, fracture dislocation of facet joints, and fractures of left transverse processes from L1 through L4, left L4 pedicle, L4 spinous process and the posterior inferior L4 vertebral body (Fig. 1b). There was retropulsion of a L4 vertebral body fragment, causing $>50 \%$ spinal canal narrowing. (Fig. 1d).

Emergency surgery was performed within $6 \mathrm{~h}$ of injury. There was spontaneous reduction of the L4-5 dislocation upon prone position (Fig. 1e), the supraspinous ligament was not disrupted from L3 to S1, and the facet capsules of L2-3 and L5-S1 were preserved. Pedicle screws were inserted to bilateral L3, right L4 and bilateral L5. Laminectomy was performed from L3 to L5 for decompression (Fig. 1f). Posterolateral fusion was performed with autogenous bone graft and tricalcium phosphate. (Fig. 1g).

Post-operative magnetic resonance imaging did not show any disruption of disc or anterior longitudinal ligaments, and the central canal was well decompressed. At 9 


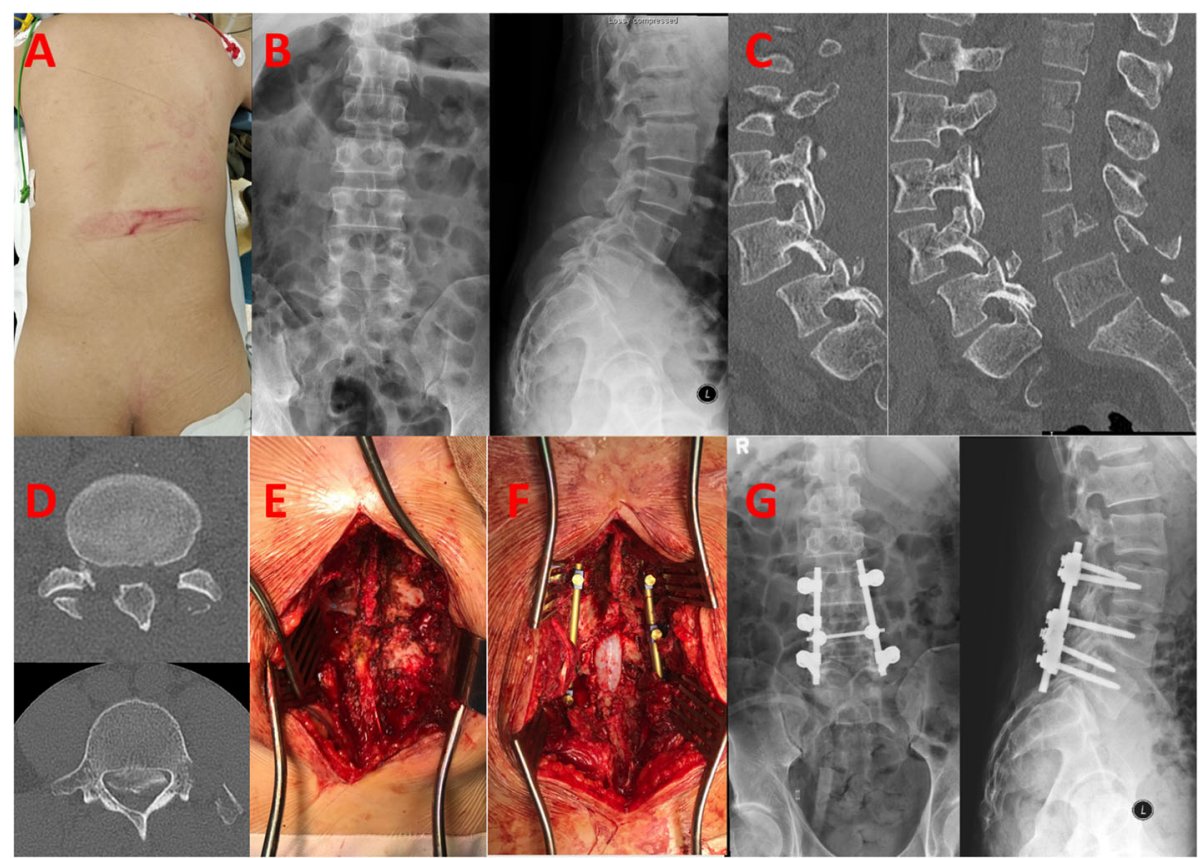

Fig. 1 a Collision site of metal bar as fulcrum. $\mathbf{b} X R$ showing grade II spondylolisthesis of $L 4$ on $L 5$, fracture dislocation of facet joints, and fractures of left transverse processes from $L 1$ through $L 4$, a fracture of posterior inferior $L 4$ vertebral body, spina bifida occulta of $L 5$. c, d. CT scan showing fracture of bilateral $L 4$ inferior articular processes, fracture of left $L 4$ transverese process, left $L 4$ pedicle and the $L 4$ spinous process, $L 4$ vertebral body fragment retropulsion causing severe spinal canal narrowing, and coronally oriented $L 4 / 5$ facets. e Spontaneous reduction of dislocation upon prone position. $\mathbf{f}$ Laminectomy and posterior spinal fusion with instrumentation. $\mathbf{g}$ Post-operative XR showing reduction of dislocation

months post-injury, he had regained sphincter control and was able to walk with frame with full neurological recovery over the right side. However, his distal muscle groups over the left side remained weak with grade $2 / 5$ ankle dorsiflexors, long toe extensors and ankle plantarflexors.

\section{Discussion}

Bilateral facet joint dislocation of L4-5 level is a rare entity, a PubMed search revealed only four reports [1-4] (Table 1), while most were based on lumbosacral (L5-S1) dislocation since described by Watson-Jones in 1940 [5, 6]. Although Watson-Jones described the hyperextension stress in the first case of reported lumbosacral dislocation, most authors have considered the main mechanism to be hyperflexion [5]. It is not until recently, that the pathophysiology of traumatic dislocations of the lumbar spine are again considered to be due to hyperextension injury $[2,4,5]$.

The mechanisms of injury in the reported cases of L4-5 dislocation were high energy motor vehicle accidents with head-on collisions, where three out of four had usage of seatbelt, and one thrown out of the vehicle. These were associated with significant posterior soft tissue injuries, including supraspinous ligaments, interspinous ligaments and facet capsules of other levels [1-4] (Table 1). Zenonos [4] proposed the pathophysiology of the injury as such: a seatbelt holds down the thoracic spine and pelvis by the shoulder harness and waist harness respectively. With the thoracic spine as a fulcrum, the forward momentum of the body and remaining thoracolumbar spine forces the spine to swing forward. The greater distance from the fulcrum, the greater the force due to a longer moment arm. At the same time, the pelvis in splinted down by waist harness and immobilized, hence there is a large extensiondistraction force at the lower lumbar and lumbosacral junction. However, high energy injuries are always complex and may be difficult to analyse and to deduce a single injury pattern.

Our case had a similar mechanism of injury but resulting from a low energy falling accident. This provides more insight on the pathophysiology of such injuries. Our patient fell with his back landing onto a metal bar with additional weights on his thighs. In this scenario, the metal bar acted as a fulcrum, with the spinal segments above and below translating posteriorly after the impact. The additional weight on his thigh forced the lumbar spine into hyperextension, which further propagated the injury. When compared to the motor vehicle accidents described previously, the relative vectors are the same. The points of fixation by seatbelts are replaced by body weights, while the momentum of body replaced by the fulcrum represented by the metal bar; both 


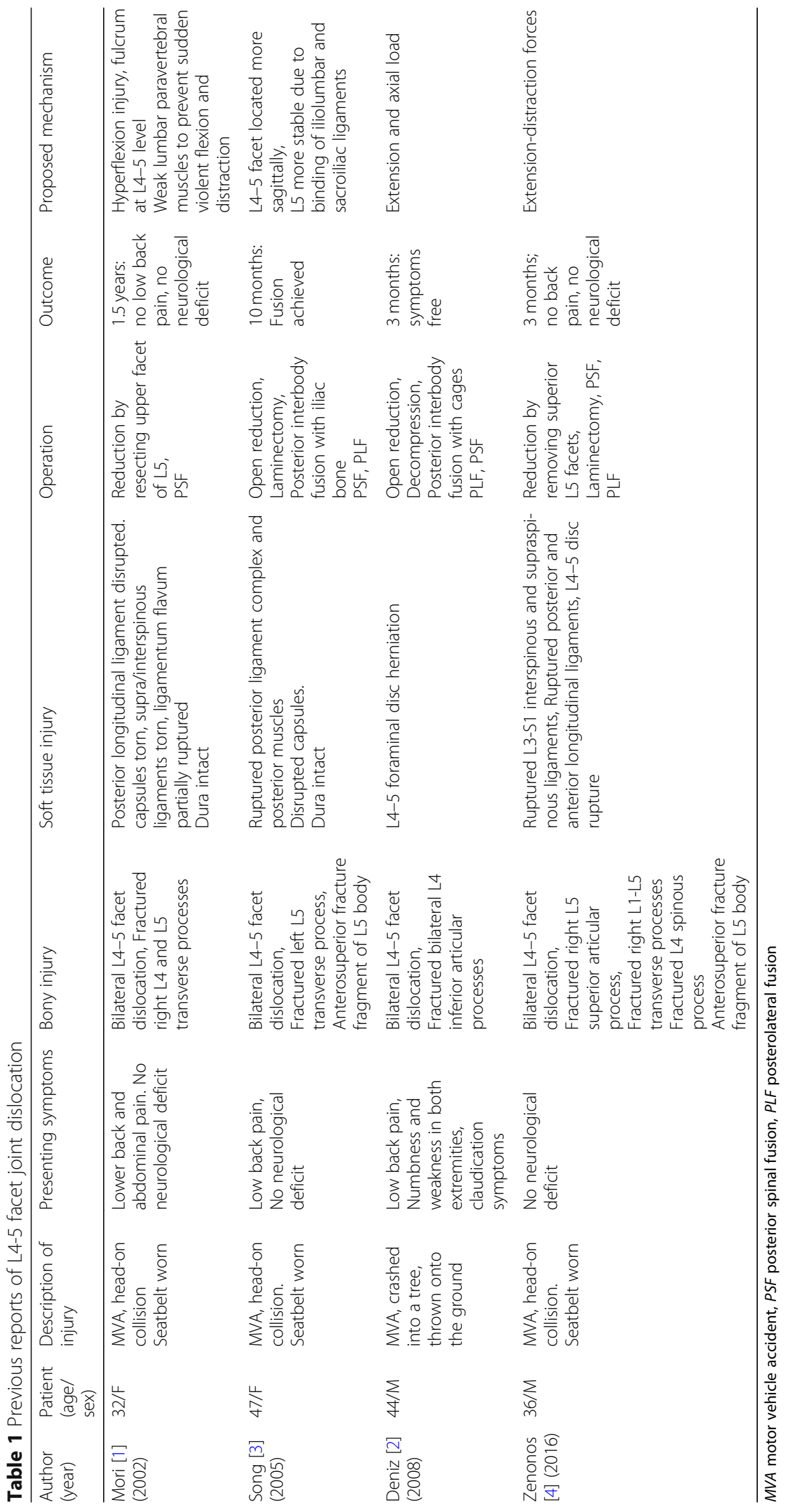


situations results in a forward motion of the lumbar spine relative to the remainder of the body, resulting in hyperextension of the lumbar spine (Fig. 2).

In the current case, the injury pattern suggested that the traumatic force is exerted by extension stress. There are fractures of the L4 spinous process, bilateral L4 inferior articular processes and L4 postero-inferior body. This is further supported by fractured transverse processes from L1-L4 as an indirect evidence of strong contractions of iliopsoas muscles to resist hyperextension. Also, the supraspinous ligament was not disrupted from L3 to S1, and the facet capsules of L2-3 and L5-S1 were preserved, hence a flexion injury is less likely. During a hyperextension injury, posterior structures experience greater compressive forces. Therefore, the spinous process fractures first, then the facet joints, then the posterior body. The soft tissue damage is secondary to the dislocation, including the disruption of joint capsules and ligamentum flavum. The extensive posterior soft tissue damage in the reported cases may be due to a hyperflexion following the hyperextension, similar to a whiplash injury of the cervical spine but "reversed" due to the points of immobilization by the seatbelts as mentioned above.

Regarding the possible level of injury, Zenosos [4] proposed that the L4-5 is biomechanically more susceptible to dislocation when compared to L5-S1 for the following reasons: 1 . The extension range of motion of L4-5 is less than L5-S1. 2. The L4-5 facet joints are oriented more sagittally when compared to L5-S1 facet joints. 3. The L5$\mathrm{S} 1$ articular complex has a stronger ligamentous support.

However, this seems contrary to the majority of cases which the dislocation occured at the L5-S1 level. There are no biomechanical studies to confirm the exact ranges of flexion or extension of individual levels. It has been shown that the facet angle consistently increased from L2-L3 to L5-S1 with regards to the sagittal plane [7]. However, it has also been demonstrated that the L4-5 and L5-S1 facet joints have high variations in facet angle depending on ethnicity [8-11].

Our patient had spina bifida occulta at L5 (Fig. 1b), which may result in a higher extension range in L5-S1 than L4-5. Hence, a larger extension reserve for hyperextension, as there is no spinous process at the posterior of L 5 to restrict extension. Also, his L4-L5 facet joints are almost in a coronal plane similar to L5-S1 facet joint (Fig. 1d). The above reasons may account for why the dislocation occurred at the L4-5 level rather than at L5-S1 resulting in a complex fracture dislocation.

We believe that the L4-5 traumatic facet fracture dislocation and the lumbosacral dislocation should be grouped into the same disease entity, as the mechanism of injury is similar. The level of injury differs in each individual as the anatomy of posterior structures is different. We have presented a case that has an anatomical variant which may have possibly explained why his injury has led to a injury at the level of L4-L5 rather than the lumbosacral junction. A spine is only as strong as its weakest link.

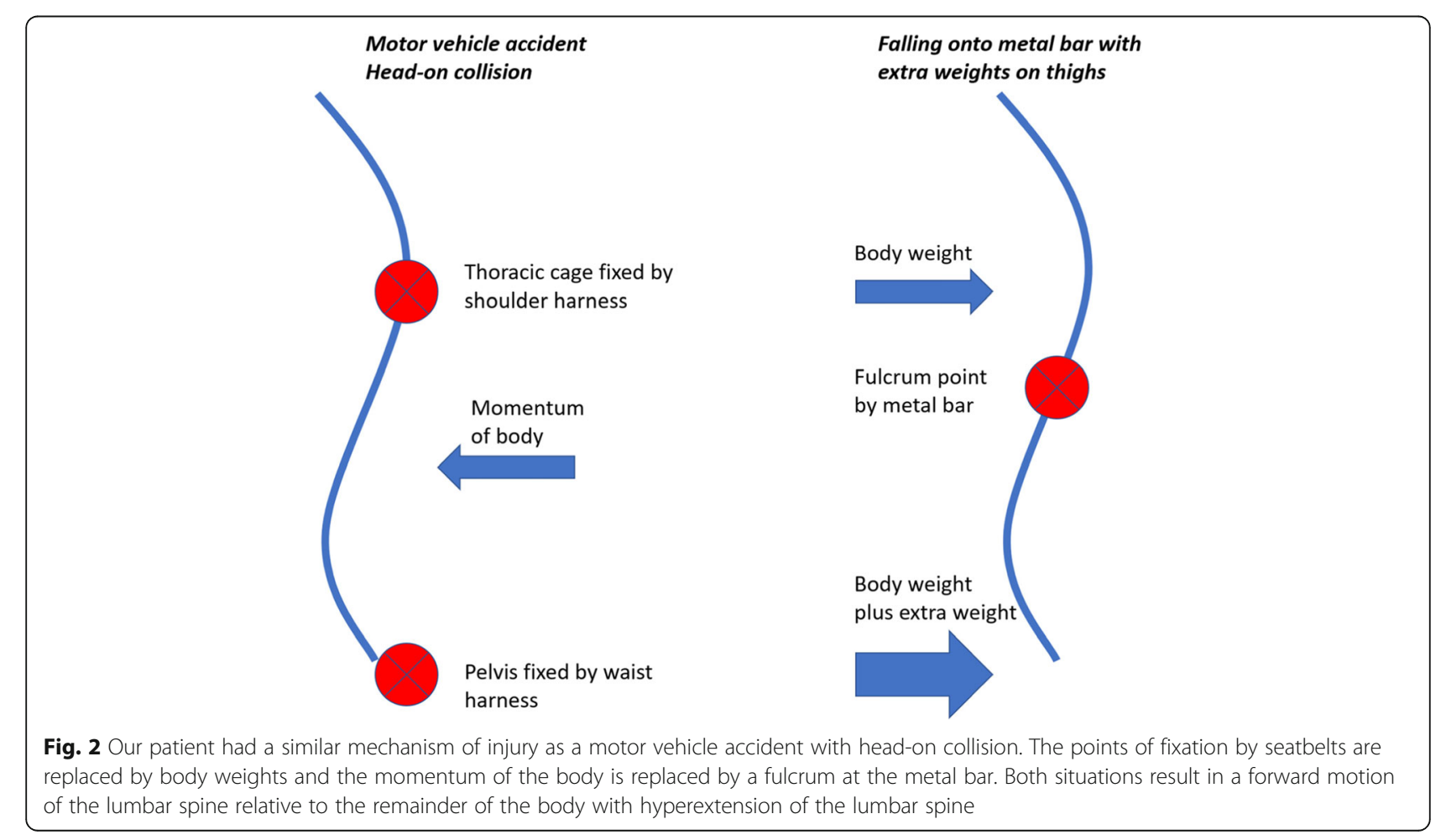




\section{Acknowledgments}

Not applicable.

\section{Authors' contributions}

KCHF drafted the work; JPYC substantively revised it. Both authors approved the submitted version, have agreed both to be personally accountable for the author's own contributions. Both authors read and approved the final manuscript.

\section{Funding}

No funding was applied.

\section{Availability of data and materials}

Data sharing is not applicable to this article as no datasets were generated or analysed furing current study.

\section{Ethics approval and consent to participate}

Not applicable.

\section{Consent for publication}

Written consent was obtained from the patient.

\section{Competing interests}

The authors declare that they have no competing interests.

Received: 10 March 2019 Accepted: 30 October 2019

Published online: 23 November 2019

\section{References}

1. Mori K, Hukuda S, Katsuura A, Saruhashi Y, Asajima S. Traumatic bilateral locked facet at L4-5: report of a case associated with incorrect use of a three-point seatbelt. Eur Spine J. 2002:11(6):602-5.

2. Deniz FE, Zileli M, Çağlı S, Kanyilmaz H. Traumatic L4-L5 spondylolisthesis: case report. Eur Spine J. 2008;17(Supplement 2):232-5.

3. Song K, Lee KB. Bilateral facet dislocation on $L 4-L 5$ without neurologic deficit. J Spinal Disord Tech. 2005;18(5):462-4.

4. Zenonos GA, Agarwal N, Monaco EA III, Okonkwo DO, Kanter AS. Traumatic L4-5 bilateral locked facet joints. Eur Spine J. 2016;25(1):129-33.

5. Saiki K, Hirabayashi S, Sakai H, Inokuchi K. Traumatic anterior lumbosacral dislocation caused by hyperextension mechanism in preexisting $L 5$ spondylolysis a case report and a review of literature. Spinal Disord Tech. 2006:19(6):455-62.

6. Watson-Jones R. Fractures and joint injuries. 1st ed. Edinburgh: E \& S Livingstone; 1940

7. Liu X, Zhao X, Long Y, Huang K, Xie D, Wang F, Chen G, et al. Facet sagittal orientation: possible role in the pathology of degenerative lumbar spinal stenosis. Spine (Phila Pa 1976). 2017:43(14):955-8.

8. Sugawara K, Katayose M, Watanabe K. The variation in the lumbar facet joint orientation in an adult Asian population and its relationship with the crosssectional area of the multifidus and erector spinae. Asian Spine J. 2016;10(5): 886-92.

9. Samartzis D, Cheung JP, Rajasekaran S, Kawaguchi Y, Acharya S, Kawakami M, et al. Critical values of facet joint angulation and tropism in the development of lumbar degenerative spondylolisthesis: an international, large-scale multicenter study by the AOSpine Asia Pacific research collaboration consortium. Global Spine J. 2016;06(05):414-21.

10. Samartzis D, Cheung JP, Rajasekaran S, Kawaguchi Y, Acharya S, Kawakami $M$, et al. Is lumbar facet joint tropism developmental or secondary to degeneration? An international, large-scale multicenter study by the AOSpine Asia Pacific research collaboration consortium. Scoliosis Spin Disord. 2016;11(1):9.

11. Williams R, Cheung JP, Goss B, Rajasekaran S, Kawaguchi Y, Acharya S, Kawakami M, et al. An international multicenter study assessing the role of ethnicity on variation of lumbar facet joint orientation and the occurrence of degenerative spondylolisthesis in Asia Pacific: a study from the AOSpine Asia Pacific research collaboration consortium. Global Spine J. 2016;06(01): 035-45.

\section{Publisher's Note}

Springer Nature remains neutral with regard to jurisdictional claims in published maps and institutional affiliations.

Ready to submit your research? Choose BMC and benefit from:

- fast, convenient online submission

- thorough peer review by experienced researchers in your field

- rapid publication on acceptance

- support for research data, including large and complex data types

- gold Open Access which fosters wider collaboration and increased citations

- maximum visibility for your research: over $100 \mathrm{M}$ website views per year

At BMC, research is always in progress.

Learn more biomedcentral.com/submissions 